Article

\title{
Anaerobic Speed Reserve, Sprint Force-Velocity Profile, Kinematic Characteristics, and Jump Ability among Elite Male Speed- and Endurance-Adapted Milers
}

\author{
Pedro Jiménez-Reyes ${ }^{1}$, Víctor Cuadrado-Peñafiel ${ }^{2}$, Juan A. Párraga-Montilla ${ }^{3} \mathbb{D}$, Natalia Romero-Franco ${ }^{4,5, * \mathbb{D}}$ \\ and Arturo Casado ${ }^{1}$ iD
}

check for updates

Citation: Jiménez-Reyes, P.; Cuadrado-Peñafiel, V.;

Párraga-Montilla, J.A.;

Romero-Franco, N.; Casado, A.

Anaerobic Speed Reserve, Sprint Force-Velocity Profile, Kinematic Characteristics, and Jump Ability among Elite Male Speed- and Endurance-Adapted Milers. Int. J. Environ. Res. Public Health 2022, 19, 1447. https://doi.org/10.3390/ ijerph19031447

Academic Editor: Paul B. Tchounwou

Received: 20 December 2021

Accepted: 25 January 2022

Published: 27 January 2022

Publisher's Note: MDPI stays neutral with regard to jurisdictional claims in published maps and institutional affiliations.

Copyright: (C) 2022 by the authors. Licensee MDPI, Basel, Switzerland. This article is an open access article distributed under the terms and conditions of the Creative Commons Attribution (CC BY) license (https:// creativecommons.org/licenses/by/ $4.0 /)$.
1 Centre for Sport Studies, Rey Juan Carlos University, E-28943 Madrid, Spain; peterjr49@hotmail.com (P.J.-R.); arturocasado1500@gmail.com (A.C.)

2 Education Faculty, Autonomous University of Madrid, E-28049 Madrid, Spain; victoriefc@yahoo.es

3 Department of Didactics of Musical, Plastic and Corporal, University of Jaén, E-23071 Jaén, Spain; jparraga@ujaen.es

4 Nursing and Physiotherapy Department, University of the Balearic Islands, E-07122 Palma de Mallorca, Spain

5 Health Research Institute of the Balearic Islands (IdISBa), E-07010 Palma de Mallorca, Spain

* Correspondence: narf52@gmail.com; Tel.: +34-971172916

\begin{abstract}
This study aimed to compare sprint, jump performance, and sprint mechanical variables between endurance-adapted milers (EAM, specialized in 1500-3000-m) and speed-adapted milers (SAM, specialized in 800-1500 $\mathrm{m}$ ) and to examine the relationships between maximal sprint speed (MSS), anaerobic speed reserve (ASR), sprint, jump performance, and sprint mechanical characteristics of elite middle-distance runners. Fifteen participants (8 EAM; 7 SAM) were evaluated to obtain their maximal aerobic speed, sprint mechanical characteristics (force-velocity profile and kinematic variables), jump, and sprint performance. SAM displayed greater MSS, ASR, horizontal jump, sprint performance, and mechanical ability than EAM $(p<0.05)$. SAM also showed higher stiffness in the 40 -m sprint $(p=0.026)$ and a higher ratio of horizontal-to-resultant force (RF) at $10 \mathrm{~m}(p=0.003)$ and RFpeak $(p=0.024)$. MSS and ASR correlated with horizontal $(r=0.76)$ and vertical $(r=0.64)$ jumps, all sprint split times $(r \leq-0.85)$, stiffness $(r=0.86)$, and mechanical characteristics $(r \geq 0.56)$ during the 100 -m sprint, and physical qualities during acceleration $(r \geq 0.66)$ and sprint mechanical effectiveness from the force-velocity profile $(r \geq 0.69)$. Season-best times in the $800 \mathrm{~m}$ were significantly correlated with MSS $(r=-0.86)$. Sprint ability has a crucial relevance in middle-distance runners' performance, especially for SAM.
\end{abstract}

Keywords: maximal force; performance; maximal power; middle-distance running

\section{Introduction}

Performance in middle-distance runners is determined by tactical decision-making and physiological and mechanical factors [1]. Success in athletic races from $800 \mathrm{~m}$ to $3000 \mathrm{~m}$ is characterized by rapid, economical, and cyclical movement patterns [2]. Athletes need to sustain running velocities at and above maximal aerobic speed (MAS), deemed as the minimum speed at which maximum oxygen uptake is attained, and develop their sprinting ability to a great extent in order to achieve successful performances at major championships [3,4]. Although running economy and MAS are considered main middledistance running performance determinants [5], recent studies also highlight the important role of anaerobic qualities [6,7] such as anaerobic speed reserve (ASR), which is the speed zone ranging from MAS to maximal sprint speed (MSS) [8,9]. Given that elite middledistance runners display high levels of MAS [5] and anaerobic capacity, it seems that ASR should be considered to understand the underpinning mechanisms explaining their performance. In addition, MSS, which represents the upper part of the ASR spectrum, 
could also be an appropriate key performance parameter in middle-distance runners, not only because it allows athletes to achieve faster paces over longer distances [6] but also because it is the way to increase their ASR.

Furthermore, ASR has been proposed to be useful in categorizing different middledistance runners' profiles (i.e., 400-800 m, 800 m, and 800-1500 m types) and identifying training models (i.e., specific prescription of high-intensity training sessions) according to these profiles [10]. In this sense, different running categories exist in each distance event, and $1500 \mathrm{~m}$ runners can be considered either speed-adapted (800-1500 m specialists) or endurance-adapted (1500-3000 m specialists) milers (SAM and EAM, respectively) [11].

In addition, current evidence fails to describe the influence of anaerobic capacity (i.e., the ability to display higher speeds than MAS and lower than MSS) on running performance and ASR in middle-distance runners. In this term, the force-velocity (F-V) profile [12,13] during a maximum speed sprint would allow to describe the mechanical effectiveness in force application (i.e., the percentage of the resultant force that is produced in the horizontal direction) at the upper limit of ASR in middle-distance runners [14], apart from helping coaches to implement individualized training programs [12,13].

Apart from anaerobic factors, several studies have shown a rising interest in mechanical parameters such as the association of stiffness with running economy (RE) and maximal velocity [2,15], or the existing differences in running kinematics (i.e., step length, frequency, and flight and contact time) among athletes of different performance levels [16] and categories [11]. However, the influence of all these mechanical parameters on running performance in middle-distance running events has not been explored sufficiently yet. Since increasing evidence suggests that performance in these events could be strongly connected to anaerobic characteristics and sprint ability [7,17], it would be useful for athletes and coaches to describe the aforementioned mechanical parameters in middle-distance runners and elucidate the relationship to performance determinants.

Therefore, the aims of the present study were: (1) to describe and compare sprint and jump performance and sprint mechanical variables between elite male SAM and EAM, and (2) to examine the relationships between MSS and ASR with sprint and jump performance and sprint mechanical variables in elite male middle-distance runners. We hypothesize that SAM will display greater sprint and jump performance and more efficient sprint mechanical responses than EAM and that MSS and ASR will significantly correlate with sprint and jump performance and efficiency of sprint mechanical responses.

\section{Materials and Methods}

\subsection{Participants}

A convenient sample of 15 elite male middle-distance running athletes (age $=24.5 \pm 4.6$ years, body mass $=63.1 \pm 4.3 \mathrm{~kg}$, height $=1.77 \pm 0.05 \mathrm{~m}$ ) voluntarily participated in this study. All athletes trained in the same training group and shared the same coach at the Sport High Performance Centre of the Spanish Government (Madrid). To conduct an exhaustive analysis, participants were classified based on their coach's perspective regarding the athletic event they were specialized in. Accordingly, eight and seven runners were considered SAM and EAM, respectively. This coach's decision was based on the target event for the season and the training characteristics being used (i.e., milers who were also targeting the $800 \mathrm{~m}$ event displayed higher intensity and lower volume in training; milers who were also targeting the 3000 m, $3000 \mathrm{~m}$ steeplechase, or $5000 \mathrm{~m}$ events displayed lower intensity and higher volume in training). Additionally, this decision was confirmed by means of analyzing the difference in recent competitive performances between shorter (i.e., $800 \mathrm{~m}$ ) and longer (i.e., $3000 \mathrm{~m}$ ) events than $1500 \mathrm{~m}$. The World Athletic open access website was used to collect the best performances achieved by participants during competition 12 months prior to testing (www.worldathletics.org (accessed on 15 December 2021)). These results were transformed into World Athletics (WA) scores [18]. If the "better" recent performance of participants was achieved in shorter events than $1500 \mathrm{~m}$, they were allocated to the SAM group, and 
if the "better" recent performance was shown in longer events than $1500 \mathrm{~m}$, they were allocated to the EAM group.

Eligibility criteria required that participants: (a) were current elite athletes, considered those who competed internationally or at senior category national championships, to accord with widely used criteria used to define elite athletes [19]; (b) had at least 5 years of systematic training experience (Table 1); (c) were free from health problems or musculoskeletal injuries that could compromise testing performance during at least 6 months prior to the beginning of the study. All the participants were informed of the study procedures and signed a written informed consent form prior to initiating the study. The study protocol adhered to the tenets of the Declaration of Helsinki and was approved by the Institutional Review Board of Pablo de Olavide University (935/CEIH/2019).

Table 1. Performance characteristics of participants.

\begin{tabular}{|c|c|c|c|c|}
\hline \multirow{2}{*}{$\begin{array}{l}\text { Competitive } \\
\text { Level }\end{array}$} & \multirow{2}{*}{$\begin{array}{l}\text { Greatest Competition in } \\
\text { Which Athletes Participated }\end{array}$} & \multirow{2}{*}{$\begin{array}{l}\text { Other Relevant } \\
\text { Information }\end{array}$} & World Athletics Scores & SB (min:s.cs) \\
\hline & & & Mean \pm SD & Mean \pm SD \\
\hline $\begin{array}{c}\text { World }(n=2) \\
\text { European }(n=11) \\
\text { National }(n=2)\end{array}$ & $\begin{array}{l}\text { Olympic Games } \\
\text { European Championships } \\
\text { National Championships }\end{array}$ & $\begin{array}{c}2 \times \text { national record holders } \\
3 \text { European medalists } \\
2 \times \text { World Championship } \\
\text { finalists } \\
7 \text { national champions }\end{array}$ & $\begin{array}{c}800 m(n=7): 987.4 \pm 120.1 \\
1500 m(n=15): 1011.6 \pm 86.0 \\
3000 m(n=5): 974.0 \pm 168.2\end{array}$ & $\begin{array}{l}800 m(n=7): 1: 51.24 \pm 4.29 \\
1500 m(n=15): 3: 47.44 \pm 6.8 \\
3000 m(n=5): 8: 32.45 \pm 27.5\end{array}$ \\
\hline
\end{tabular}

$\mathrm{SB}$, season-best time; SD, standard deviation.

\subsection{Study Design}

A cross-sectional study was designed in two different testing sessions, with 1 week apart: (1) participants performed an incremental treadmill test through which physiological performance outcomes were obtained; and (2) participants performed a testing battery in this order: maximal vertical and horizontal jumps and maximal $40 \mathrm{~m}$ and $100 \mathrm{~m}$ sprints. Prior to the beginning of the second testing session, all athletes performed a 15-min warmup and a familiarization process to ensure the correct execution of all testing procedures. In addition, athletes were asked to avoid intense exercise in the $24 \mathrm{~h}$ before testing, apart from ensuring that the training load was similar for all athletes in the last 3 days prior to testing to avoid fatigue-affected results. These sessions were carried out in the High Performance Centre of the city in June 2019, which refers to the competitive period of all the athletes participating in the study.

\subsection{Testing Session 1}

Maximal aerobic speed (MAS): The maximal aerobic speed was determined through an incremental treadmill test (Technogym, Exite Run 600, Cesena, Italy) that was performed 1 week before the aforementioned testing session. All participants carried out a standardized warm-up consisting of low-intensity running and, thus, started the test at $8.0 \mathrm{~km} \cdot \mathrm{h}^{-1}$, with $2 \%$ as the treadmill slope and progressive increments of $0.5 \mathrm{~km} \cdot \mathrm{h}^{-1}$ every $30 \mathrm{~s}$ until exhaustion. Exhaustion was considered when the runners volitionally declared their incapacity to continue at the predetermined pace. During the test, gas analyses were conducted since the participants breathed through a low dead space $(90 \mathrm{~mL})$, low resistance $(5.5 \mathrm{~cm}$ $\mathrm{H}_{2} \mathrm{O}$ at $510 \mathrm{~L} \cdot \mathrm{min}^{-1}$ ) facemask, and turbine assembly. Gases were drawn continuously from the facemask to a breath-by-breath gas analyzer (Fitmate Pro, Cosmed, Rome, Italy) through a $2 \mathrm{~m}$ sampling line $(0.5 \mathrm{~mm}$ internal diameter $)$ and were analyzed for $\mathrm{O}_{2}$ and $\mathrm{CO}_{2}$ (with a $200 \mathrm{~ms}$ delay). A turbine volume transducer (Interface Associates, Alifovieja, CA, USA) determined the expired volumes. Prior to each test, the breath-by-breath gas analyzer was calibrated by using gas mixtures (Linde Gas, London, UK) of concentrations previously known. The turbine was also calibrated prior to each test with a $3 \mathrm{~L}$ calibration syringe (Hans Rudolf, Shawnee, KS, USA). Oxygen uptake was calculated and displayed on a breath-by-breath basis. A computer was used to integrate the volume and concentration signals by converting values from analog to digital format. In this conversion, the 
delay of the gas transit through the capillary and the room temperature was taken into account. MAS was considered as the slowest speed at which maximum oxygen uptake was attained [5].

Anaerobic speed reserve (ASR): ASR was calculated as the difference between MAS and MSS. ASR is a good reflection of the speed range that an athlete possesses, considering these two milestones. With this information, it is possible to calculate the speed reserve ratio (SRR) as the coefficient of "maximal sprint speed $\left(\mathrm{km} \cdot \mathrm{h}^{-1}\right) /$ maximal aerobic speed $\left(\mathrm{km} \cdot \mathrm{h}^{-1}\right)^{\prime \prime}$.

\subsection{Testing Session 2}

All participants performed a 15-min warm-up consisting of $5 \mathrm{~min}$ of jogging and $5 \mathrm{~min}$ of lower limb dynamic stretching. During the last $5 \mathrm{~min}$, as part of the specific warm-up, participants also performed three progressive sprints of $40 \mathrm{~m}$ at 50\%, 70\%, and 90\% effort. As a familiarization process, all athletes performed progressive trials in the case of jumps and progressive accelerations from the starting line in the case of races.

Vertical jump — countermovement (CMJ): Just after warming up and familiarization, the runners carried out a maximum vertical jump. They started from an upright position, with their hands on their waists. Thus, they performed a countermovement by flexing their knees up to $90^{\circ}$ and jumping as high as possible. During the flight phase of the jump, they should maintain their knees extended up to $180^{\circ}$, without hyperextending their hips [20].

Horizontal jump—standing long jump (SLJ): Athletes were instructed to perform a maximal horizontal jump from a starting line, with both feet simultaneously and arms swinging, and without a run-up. The maximal metered performance was measured by taking into account the rear part of the most indented heel [21].

For both vertical and horizontal jumps, participants performed three trials, with 2 min as the inter-trial passive recovery, and the best one was recorded (in meters). A sports professional external to the investigation supervised the correct execution of jumps, and an OptoGait Photoelectric Cell System (OptoGait, Microgate, Bolzano, Italy) was used.

$40 \mathrm{~m}$ sprint: After $4 \mathrm{~min}$ of rest, participants performed three maximal sprints of $40 \mathrm{~m}$, with $4 \mathrm{~min}$ as the inter-trial period of rest. The fastest one was considered for the analysis. Athletes were instructed to start from a crouching position (staggered stance). A previously validated simple field method was used to compute sprint performance and mechanical outputs [13]. A Stalker Acceleration Testing System (ATS) II radar device (Stalker ATS II, Applied Concepts, Dallas, TX, USA) at $46.9 \mathrm{~Hz}$ was employed to collect velocity-time data of each sprint. The radar device was attached to a tripod $10 \mathrm{~m}$ from the starting line at a height of $1 \mathrm{~m}$, which corresponded to the height of participants' center of mass. Based on Samozino's method, sprint mechanical variables were obtained from the velocity-time data $[13,14]$. This validated method is a macroscopic biomechanical model to estimate external horizontal force production during sprinting from the velocity of the center of mass using the inverse dynamic approach [14]. The outcomes regarding the F-V profile were: maximal theoretical force (F0), maximal theoretical velocity (V0), F-V slope, maximal power (Pmax), decrease in the ratio of horizontal-to-resultant force (DRF), maximal ratio of horizontal-to-resultant force (RFpeak), and this same variable at $10 \mathrm{~m}$ (RF_10m). DRF and RFpeak are commonly employed to assess mechanical effectiveness and have been correlated with sprint performance. From the data of this test, we also calculated MSS. We also obtained sprint split times at $10 \mathrm{~m}, 20 \mathrm{~m}, 30 \mathrm{~m}$, and $40 \mathrm{~m}$.

$100 \mathrm{~m}$ sprint: After 4 min of rest, athletes performed two maximal sprints of $100 \mathrm{~m}$ from a crouching position (staggered stance), with $10 \mathrm{~min}$ of rest between sprints. For stride pattern/mechanical variables and partial times, an optoelectronic system (Optojump Next Microgate, Bolzano, Italy) was installed on the lane of an indoor track to obtain running kinematics from 30 to $40 \mathrm{~m}$ during the maximum velocity phase and from 80 to $90 \mathrm{~m}$ during the decrement of velocity phase. This material permits measurement of contact time on the floor (CT), flight time (FT), step time (ST), stride length (SL), stride flight (SF), and step velocity (SV). SL asymmetry (SLasy) was calculated as the absolute 
difference of distance covered on three left-foot strides minus the distance covered on three right-foot strides. SR, SL, FT, and CT were measured and averaged from the third up to the eighth last stride of the approach. Furthermore, partial times were collected for $21-$ to- $30 \mathrm{~m}$, $30 \mathrm{~m}, 60 \mathrm{~m}, 80 \mathrm{~m}$, and $100 \mathrm{~m}$. For vertical and leg stiffness, step characteristics of CT and FT sampled at $1000 \mathrm{~Hz}$ were captured via a series of ground-based photoelectric cells (Microgate: OptoJump, Bolzano, Italy) positioned between 40 and $49 \mathrm{~m}$ of the sprint track. This part of the sprint is often the segment where runners achieved Vmax (as shown in pilot testing). The spring-mass model $[22,23]$ was used to compute the mechanical leg behavior during the ground contact. The calculation of peak vertical ground reaction force (Fmax), vertical stiffness (Kvert), and leg stiffness (Kleg) was based on the method validated by Morin et al. (2005) [24].

\subsection{Statistical Analyses}

Descriptive data are presented as means and standard deviations. The degree of the linear relationship between variables was examined using Pearson's product moment correlation. Independent sample $t$-tests and Cohen's $d$ effect size (ES) with $95 \%$ confidence intervals were used to compare the sprint mechanical F-V profile (F0, V0, Pmax, DRF, and RFpeak), ASR, mechanical variables of stride patterns, and MSS between types of middle-distance runners. The scale used for interpreting the magnitude of the effect size was specific to training research: negligible $(<0.2)$, small $(0.2-0.49)$, moderate (0.5-0.79), and large $(\geq 0.8)$ [25]. Statistical significance was set at $p \leq 0.05$. Data were analyzed using SPSS 20.0 software (SPSS Inc. Chicago, IL, USA) and Office Excel 2010 (Microsoft Corporation, Redmond, WA, USA).

\section{Results}

Table 2 shows the descriptive outcomes of aerobic-anaerobic variables, sprint mechanical profile, and performance of SAM and EAM. Significant differences were found between groups in variables describing aerobic-anaerobic performance, SLJ distance, $100 \mathrm{~m}$ sprint performance, and sprint mechanical profile and effectiveness. In all variables, SAM displayed a greater performance than EAM.

Table 3 shows the correlations between MSS and ASR, and the remaining sprint mechanical characteristics and physiological performance determinants derived from the incremental treadmill test that participants carried out in the study. Season-best performances in $800 \mathrm{~m}$ showed a significantly negative and small-to-moderate correlation with ASR $(p<0.05)$. ASR and MSS showed positive and moderate-to-high correlations with performance in both maximal jumps, mainly for results related to SLJ $(r>0.75, p<0.01)$ (Table 3). It is also important to highlight the significantly high-to-very high negative correlation $(r>-0.7, p<0.01)$ observed between ASR and MSS and all $100 \mathrm{~m}$ sprint split times, especially those between MSS and split times belonging to longer distances than $30 \mathrm{~m}$ $(r>-0.9, p<0.001)$ (Table 3). ASR and MSS showed significantly positive and moderateto-very high correlations with all F-V profile variables $(r>0.6, p<0.05)$, except for $\mathrm{F}-\mathrm{V}$ profile and DRF, which did not show any significant correlation $(p>0.05)$. In addition, the correlations observed between both ASR and MSS and V0 were very high and positive $(r>0.9, p<0.001)$ (Table 3$)$. No other significant correlations were found $(p>0.05)$. 
Table 2. Aerobic-anaerobic variables, sprint and jump performance, and sprint mechanical characteristics of participants in the study.

\begin{tabular}{|c|c|c|c|c|c|c|c|c|}
\hline & & & \multicolumn{3}{|c|}{$\begin{array}{l}\text { SAM Athletes } \\
\quad(n=7)\end{array}$} & \multicolumn{3}{|c|}{$\begin{array}{l}\text { EAM Athletes } \\
\quad(n=8)\end{array}$} \\
\hline & & & Mean & \pm & SD & Mean & \pm & SD \\
\hline \multirow{4}{*}{\multicolumn{2}{|c|}{ Aerobic-anaerobic }} & MSS (km/h) & 33.02 & \pm & 1.19 & $30.66^{* * d}$ & \pm & 1.18 \\
\hline & & $\mathrm{vVO}_{2 \max }$ & 21.90 & \pm & 0.59 & 21.96 & \pm & 0.98 \\
\hline & & ASR (km/h) & 11.12 & \pm & 0.98 & $8.71^{* * d}$ & \pm & 1.48 \\
\hline & & SRR & 1.51 & \pm & 0.05 & $1.40 * * b$ & \pm & 0.08 \\
\hline \multirow{2}{*}{\multicolumn{2}{|c|}{ Maximal jump }} & $\mathrm{CMJ}(\mathrm{cm})$ & 39.64 & \pm & 6.51 & 34.49 & \pm & 6.31 \\
\hline & & SLJ (m) & 2.40 & \pm & 0.19 & $2.16^{* b}$ & \pm & 0.14 \\
\hline \multirow{14}{*}{$100 \mathrm{~m}$ sprint } & \multirow{6}{*}{$\begin{array}{c}\text { Stride pattern } \\
\text { (mechanical variables) }\end{array}$} & CT (s) & 0.110 & \pm & 0.008 & 0.118 & \pm & 0.009 \\
\hline & & FT (s) & 0.133 & \pm & 0.011 & 0.133 & \pm & 0.008 \\
\hline & & ST (s) & 0.243 & \pm & 0.013 & 0.251 & \pm & 0.008 \\
\hline & & SL (m) & 2.103 & \pm & 0.125 & 2.083 & \pm & 0.126 \\
\hline & & $\mathrm{SF}(\mathrm{m})$ & 4.126 & \pm & 0.221 & 3.983 & \pm & 0.134 \\
\hline & & $\mathrm{SV}(\mathrm{m} / \mathrm{s})$ & 8.663 & \pm & 0.573 & 8.260 & \pm & 0.452 \\
\hline & \multirow{5}{*}{ Time $100 \mathrm{~m}$} & 21_30 m (s) & 0.98 & \pm & 0.04 & $1.03 * a$ & \pm & 0.04 \\
\hline & & $30 \mathrm{~m}(\mathrm{~s})$ & 4.22 & \pm & 0.12 & $4.50 * * b$ & \pm & 0.15 \\
\hline & & $60 \mathrm{~m} \mathrm{(s)}$ & 7.44 & \pm & 0.24 & $7.84 * b$ & \pm & 0.27 \\
\hline & & $80 \mathrm{~m}(\mathrm{~s})$ & 9.62 & \pm & 0.34 & $10.20 * * c$ & \pm & 0.33 \\
\hline & & $100 \mathrm{~m}(\mathrm{~s})$ & 11.84 & \pm & 0.45 & $12.61^{* * c}$ & \pm & 0.43 \\
\hline & \multirow{3}{*}{ Stiffness } & Fmax (BW) & 3.48 & \pm & 0.18 & 3.25 & \pm & 0.30 \\
\hline & & Kvert $(\mathbf{k N} / \mathrm{m})$ & 79.58 & \pm & 11.21 & $67.57 * d$ & \pm & 7.20 \\
\hline & & Kleg (kN/m) & 14.20 & \pm & 1.65 & 12.32 & \pm & 2.14 \\
\hline \multirow{7}{*}{$\begin{array}{l}40 \mathrm{~m} \text { sprint } \\
(\mathrm{F}-\mathrm{V} \text { profile) }\end{array}$} & \multirow{4}{*}{$\begin{array}{l}\text { Physical qualities during } \\
\text { acceleration }\end{array}$} & V0 (m/s) & 9.68 & \pm & 0.34 & $8.95^{* * c}$ & \pm & 0.34 \\
\hline & & F0 (N/kg) & 7.18 & \pm & 0.34 & $6.58 * c$ & \pm & 0.57 \\
\hline & & $\operatorname{Pmax}(W / k g)$ & 17.24 & \pm & 1.30 & $14.62 * * d$ & \pm & 1.57 \\
\hline & & FV-profile & -47.10 & \pm & 4.38 & -46.13 & \pm & 3.67 \\
\hline & \multirow{3}{*}{ Mechanical effectiveness } & RF_10m & 0.336 & \pm & 0.015 & $0.304^{* * a}$ & \pm & 0.018 \\
\hline & & RF_peak & 0.500 & \pm & 0.020 & 0.466 *a & \pm & 0.029 \\
\hline & & DRF & -0.066 & \pm & 0.003 & -0.066 & \pm & 0.005 \\
\hline
\end{tabular}

ASR, anaerobic speed reserve; CMJ, countermovement jump; CT, contact time; DRF, decrease in the ratio of horizontal-to-resultant force; EAM, endurance-adapted athletes (1500-3000 m); F0, maximal theoretical force; Fmax, peak vertical group reaction force; FT, flight time; FV, force-velocity; Kleg, leg stiffness; Kvert, vertical stiffness; MSS, maximal sprint speed; Pmax, maximal power; RF, ratio of horizontal-to-resultant force; SAM, sprint-adapted athletes (800-1500 m); SD, standard deviation; SLJ, single long jump; SRR, sprint reserve ratio; ST, step time; SL, stride length; SF, stride flight; SV, step velocity; V0, maximal theoretical velocity; $\mathrm{vVO}_{2 \max }$ velocity at maximal oxygen uptake. Scheme $0 .{ }^{*} p<0.05 ;{ }^{* *} p<0.01$; ${ }^{a}$ negligible effect size $(<0.2)$; ${ }^{\mathrm{b}}$ small effect size $(0.2-0.49) ;{ }^{c}$ moderate effect size $(0.5-0.79) ;{ }^{d}$ large effect size $(\geq 0.8)$. 
Table 3. Correlations between Maximal Sprint Speed and Anaerobic Speed Reserve with sprint, jump performance and sprint mechanical characteristics of participants.

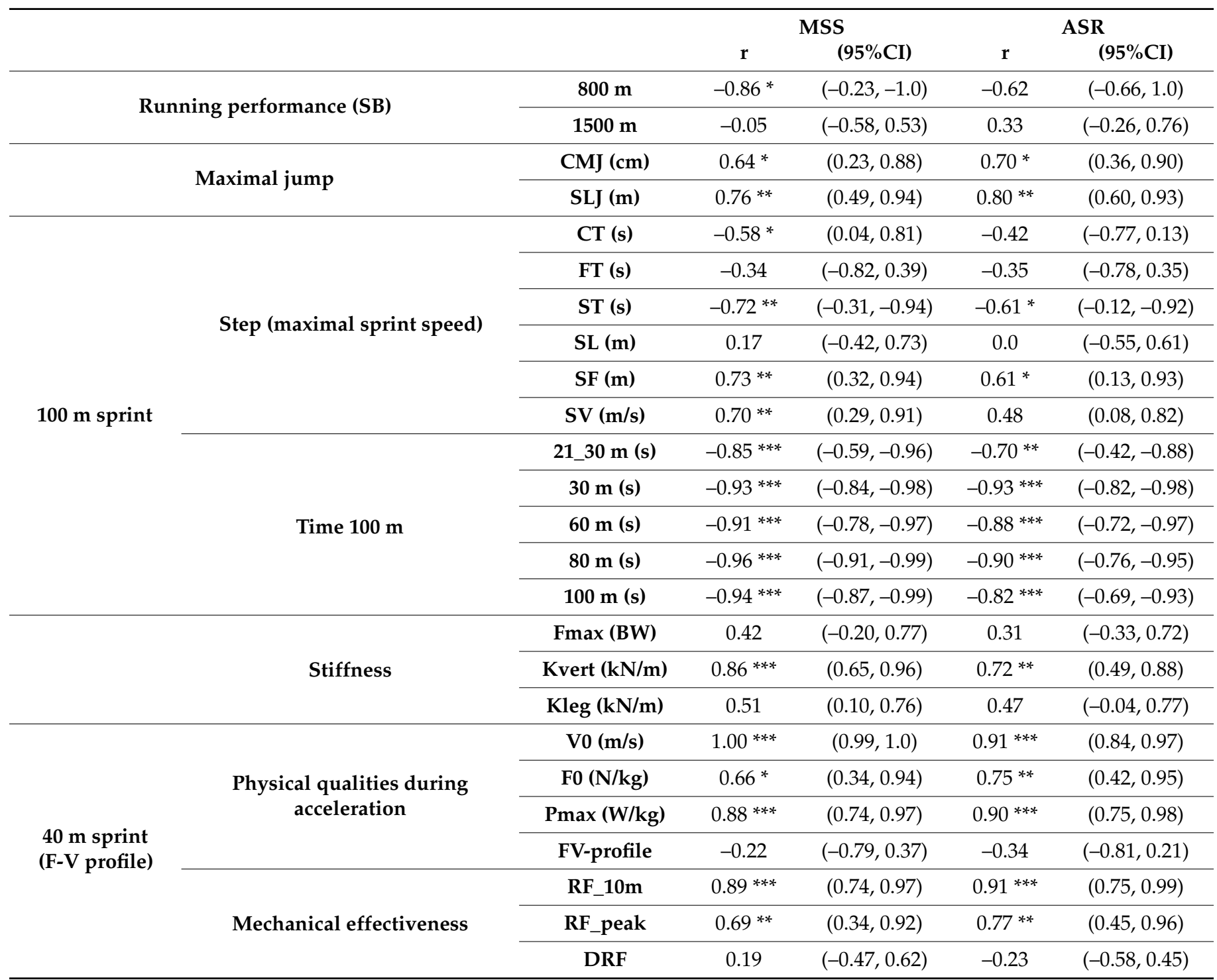

ASR, anaerobic speed reserve; CMJ, countermovement jump; CT, contact time; DRF, decrease in the ratio of horizontal-to-resultant force; EAM, endurance-adapted athletes (1500-3000 m); F0, maximal theoretical force; FMax, peak vertical group reaction force; FT, flight time; FV, force-velocity; Kleg, leg stiffness; Kvert, vertical stiffness; MSS, maximal sprint speed; Pmax, maximal power; RF, ratio of horizontal-to-resultant force; SAM, sprint-adapted athletes (800-1500 m); SB, season best; SLJ, single long jump; ST, step time; SL, stride length; SF, stride flight; SV, step velocity; V0, maximal theoretical velocity; ${ }^{*} p<0.05 ;{ }^{* *} p<0.01 ;{ }^{* * *} p<0.001$.

\section{Discussion}

The main finding of this study was a large significant correlation between $800 \mathrm{~m}$ performance and MSS, despite the lack of significant correlations between $800 \mathrm{~m}$ or $1500 \mathrm{~m}$ performance with ASR. In addition, jumping ability, stiffness, $100 \mathrm{~m}$ sprint performance, and F-V mechanical determinants were highly correlated with both ASR and MSS.

The large correlation observed between MSS and $800 \mathrm{~m}$ performance is in line with findings from Sandford et al., who reported an influence of ASR on the variability of running performance in elite $800 \mathrm{~m}$ runners when assuming similar MAS values and, therefore, the ASR was determined by MSS [7]. Although results from the present study indicate that ASR was not significantly correlated with $800 \mathrm{~m}$ performance, the correlation was higher than that observed with $1500 \mathrm{~m}$ performance. If we consider that the use of aerobic metabolism is greater with event distance ( $66 \%$ in $800 \mathrm{~m}$ vs. $88 \%$ in $1500 \mathrm{~m}$ ) [26], 
the influence of ASR on performance was lower in $1500 \mathrm{~m}$ than $800 \mathrm{~m}$ in the present study. Although these results would indicate that measuring ASR might be useless [27], ASR has been found effective in prescribing individualized training programs at higher intensities than MAS [28]. Additionally, MSS was correlated with $800 \mathrm{~m}$ performance, representing a performance determinant, as previous studies showed in longer distance running events such as $5000 \mathrm{~m} \mathrm{[29]} \mathrm{and} \mathrm{10,000} \mathrm{m} \mathrm{[17].} \mathrm{Although} \mathrm{our} \mathrm{results} \mathrm{did} \mathrm{not} \mathrm{report} \mathrm{a} \mathrm{significant}$ correlation between MSS and 1500 m performance, it has been previously noted that pacing profiles and tactical behaviors in middle-distance running races can be very different during "meet" than major championship races. In the case of "meet" races, the goal is to achieve the overall fastest possible performance, while during major championships, athletes aim to achieve the highest finishing position [30]. In this sense, championship races are characterized by slower races than "meets," with a fast endspurt [3,4]. Therefore, developing MSS during training is also important in elite middle-distance runners, especially for $800 \mathrm{~m}$.

In addition, SAM showed longer SLJ than EAM, and SLJ and CMJ performances significantly correlated with both MSS and ASR. These findings match with those from Maulder and Cronin, who found that both vertical and horizontal jump abilities correlated with sprint performance in the male sports population [21].

In the case of the $100 \mathrm{~m}$ sprint, although no differences were observed between SAM and EAM in any of the kinematic variables, ST and SF showed significant correlations with MSS and ASR and SV and CT with MSS. In line with our results, Brughelli et al. reported that rugby players increased their stride rate and SF and reduced their CT as long as they were reducing their speed when subsequently conducting sprinting bouts of increasing distances [31]. The relationships found between kinematic variables and ASR in the present study may be associated with the greater ASR found in SAM compared with EAM. In this line, $100 \mathrm{~m}$ performance was greater in SAM and highly correlated with both MSS and ASR. These findings could be explained by a greater MSS observed in SAM compared with EAM, while MAS remained similar for both groups. The differences found in MSS between both groups agree with the findings by Casado et al. [11].

In the same line, SAM displayed a greater stiffness than EAM. This finding would be expected considering the higher MSS displayed by $800 \mathrm{~m}$ runners than that in $1500 \mathrm{~m}$ runners [6,7,32]. Our results also showed that Kvert significantly correlated with both MSS and ASR. These findings match with previous research that found similar values in various running conditions $[15,33,34]$. Our results also agree with those from previous studies that confirmed the important role of stiffness in running economy $[15,35,36]$, thereby reducing the energy cost for a given velocity and MSS.

If we consider the F-V profile components, SAM displayed higher values for F0, V0, Pmax, Power Pmax, RF_10m, and RFpeak than EAM, with large significant correlations between these variables and both MSS and ASR. In this line, previous studies have shown that a higher F0 was more effective on the development of short accelerations in hurdlers and sprinters $[37,38]$. As we aforementioned, middle-distance runners with high F0 may be able to perform sudden accelerations during championship races to successfully cope with tactical strategies during championship races [3,30]. Similarly, V0 has been associated with the ability to produce long accelerations and reach a high sprint velocity [12], which would be paramount during middle-distance running races [3,4]. In addition, DRF and RFpeak characterize mechanical effectiveness during sprint running [14].

The main limitation of the present study refers to the small sample size. However, the sample quality is high, given the outstanding performance level of participants. A secondary limitation of the present study relies on its observational character rather than interventional. In this sense, further studies should focus on implementing different training characteristics that may influence the development of sprint performance and that of its mechanical determinants, leading to performance improvement in middledistance runners.

As practical applications, coaches should consider monitoring and developing sprinting ability in middle-distance runners to improve $800 \mathrm{~m}$ performance during championship 
races. To this end, it is important to decrease contact time and increase stiffness and stride flight time during sprint by monitoring $100 \mathrm{~m}$ performance, jumping ability, and F-V profiles across the season. The development of these parameters may be associated with an improved ability to generate a higher speed during critical moments of a race, with greater mechanical effectiveness at high velocities.

\section{Conclusions}

Elite male SAM displayed better horizontal jump and sprint performances than elite male EAM, as well as greater efficiency in sprint mechanical variables such as stiffness, physical qualities during acceleration, and mechanical effectiveness. These differences were not shown in vertical jump performance and stride pattern during sprint. In addition, MSS and ASR highly correlated with sprint and jump performances, stiffness, physical qualities during acceleration, and those related to mechanical effectiveness. Some kinetic variables during sprint such as ST and SF also correlated with MSS and ASR, and SV and CT only did so with MSS. A large correlation was shown between $800 \mathrm{~m}$ performance and MSS.

Practitioners should consider that sprinting ability is strongly related to performance in middle-distance runners, especially in those specialized in shorter races like the 800 and $1500 \mathrm{~m}$.

Author Contributions: Conceptualization, P.J.-R., V.C.-P. and A.C.; methodology, P.J.-R., J.A.P.-M. and A.C.; software, P.J.-R., V.C.-P. and N.R.-F.; validation, P.J.-R., V.C.-P. and J.A.P.-M.; formal analysis, N.R.-F. and A.C.; investigation, P.J.-R., V.C.-P. and J.A.P.-M.; resources, P.J.-R., V.C.-P., J.A.P.-M. and A.C.; data curation.; V.C.-P. and N.R.-F.; writing-original draft preparation, P.J.-R., V.C.-P., N.R.-F. and A.C.; writing-review and editing, P.J.-R., N.R.-F. and A.C.; visualization, P.J.-R., V.C.-P. and N.R.-F.; supervision, J.A.P.-M. and A.C.; project administration, J.A.P.-M. and A.C. All authors have read and agreed to the published version of the manuscript.

Funding: This research received no external funding.

Institutional Review Board Statement: The study was conducted in accordance with the Declaration of Helsinki and approved by the Institutional Review Board of Pablo de Olavide University (protocol number 935/CEIH/2019).

Informed Consent Statement: Informed consent was obtained from all subjects involved in the study.

Data Availability Statement: The data presented in this study are available on request from the corresponding author. The data are not publicly available due to privacy.

Acknowledgments: Authors would like to gratefully thank the coach and the athletes participating in this study for their willingness to support the research efforts employed to conduct it.

Conflicts of Interest: The authors declare no conflict of interest.

\section{References}

1. Sandford, G.N.; Stellingwerff, T. "Question Your Categories": The Misunderstood Complexity of Middle-Distance Running Profiles With Implications for Research Methods and Application. Front. Sport. Act. Living 2019, 1, 28. [CrossRef] [PubMed]

2. Rogers, S.A.; Whatman, C.S.; Pearson, S.N.; Kilding, A.E. Assessments of Mechanical Stiffness and Relationships to Performance Determinants in Middle-Distance Runners. Int. J. Sports Physiol. Perform. 2017, 12, 1329-1334. [CrossRef] [PubMed]

3. Casado, A.; Renfree, A. Fortune Favors the Brave: Tactical Behaviors in the Middle-Distance Running Events at the 2017 IAAF World Championships. Int. J. Sports Physiol. Perform. 2018, 26, 1-6. [CrossRef] [PubMed]

4. Hanley, B.; Stellingwerff, T.; Hettinga, F.J. Successful Pacing Profiles of Olympic and IAAF World Championship Middle-Distance Runners Across Qualifying Rounds and Finals. Int. J. Sports Physiol. Perform. 2019, 14, 894-901. [CrossRef] [PubMed]

5. Ingham, S.A.; Whyte, G.P.; Pedlar, C.; Bailey, D.M.; Dunman, N.; Nevill, A.M. Determinants of 800-m and 1500-m running performance using allometric models. Med. Sci. Sports Exerc. 2008, 40, 345-350. [CrossRef] [PubMed]

6. Sandford, G.N.; Kilding, A.E.; Ross, A.; Laursen, P.B. Maximal Sprint Speed and the Anaerobic Speed Reserve Domain: The Untapped Tools that Differentiate the World's Best Male 800 m Runners. Sport. Med. 2019, 49, 843-852. [CrossRef]

7. Sandford, G.N.; Allen, S.V.; Kilding, A.E.; Ross, A.; Laursen, P.B. Anaerobic Speed Reserve: A Key Component of Elite Male 800-m Running. Int. J. Sports Physiol. Perform. 2019, 14, 501-508. [CrossRef] 
8. Moir, G.L.; Brimmer, S.M.; Snyder, B.W.; Connaboy, C.; Lamont, H.S. Mechanical Limitations to Sprinting and Biomechanical Solutions: A Constraints-Led Framework for the Incorporation of Resistance Training to Develop Sprinting Speed. Strength Cond. J. 2018, 40, 47-67. [CrossRef]

9. Buchheit, M.; Samozino, P.; Glynn, J.A.; Michael, B.S.; Al Haddad, H.; Mendez-Villanueva, A.; Morin, J.B. Mechanical determinants of acceleration and maximal sprinting speed in highly trained young soccer players. J. Sports Sci. 2014, 32, 1906-1913. [CrossRef]

10. Sandford, G.N.; Laursen, P.B.; Buchheit, M. Anaerobic Speed/Power Reserve and Sport Performance: Scientific Basis, Current Applications and Future Directions. Sports Med. 2021, 51, 2017-2028. [CrossRef]

11. Casado, A.; Renfree, A.; Jaenes-Sánchez, J.C.; Cuadrado-Peñafiel, V.; Jiménez-Reyes, P. Differentiating Endurance-and SpeedAdapted Types of Elite and World Class Milers According to Biomechanical, Pacing and Perceptual Responses during a Sprint Interval Session. Int. J. Environ. Res. Public Health 2021, 18, 2448. [CrossRef] [PubMed]

12. Morin, J.B.; Samozino, P. Interpreting power-force-velocity profiles for individualized and specific training. Int. J. Sports Physiol. Perform. 2016, 11, 267-272. [CrossRef] [PubMed]

13. Samozino, P.; Morin, J.B.; Hintzy, F.; Belli, A. A simple method for measuring force, velocity and power output during squat jump J. Biomech. 2008, 41, 2940-2945. [CrossRef] [PubMed]

14. Morin, J.-B.; Edouard, P.; Samozino, P. Technical ability of force application as a determinant factor of sprint performance. Med. Sci. Sports Exerc. 2011, 43, 1680-1688. [CrossRef]

15. Li, F.; Newton, R.U.; Shi, Y.; Sutton, D.; Ding, H. Correlation of Eccentric Strength, Reactive Strength, and Leg Stiffness with Running Economy in Well-Trained Distance Runners. J. Strength Cond. Res. 2021, 35, 1491-1499. [CrossRef]

16. Hanon, C.; Bernard, O.; Rabate, M.; Claire, T. Effect of two different long-sprint training regimens on sprint performance and associated metabolic responses. J. Strength Cond. Res. 2012, 26, 1551-1557. [CrossRef]

17. Yamanaka, R.; Ohnuma, H.; Ando, R.; Tanji, F.; Ohya, T.; Hagiwara, M.; Suzuki, Y. Sprinting Ability as an Important Indicator of Performance in Elite Long-Distance Runners. Int. J. Sports Physiol. Perform. 2020, 15, 141-145. [CrossRef]

18. Spiriev, A. Scoring Tables for Men's events. In IAAF Scoring Tables of Athletics; 2018 Revised Edition; Monte Carlo, Monaco, 2019; Available online: https:/ / www.worldathletics.org/news/iaaf-news/scoring-tables-2017 (accessed on 25 January 2017).

19. Swann, C.; Moran, A.; Piggott, D. Defining elite athletes: Issues in the study of expert performance in sport psychology. Psychol Sport Exerc. 2015, 16, 3-14. [CrossRef]

20. Jiménez-Reyes, P.; Samozino, P.; Cuadrado-Peñafiel, V.; Conceição, F.; González-Badillo, J.J.; Morin, J.B. Effect of countermovement on power-force-velocity profile. Eur. J. Appl. Physiol. 2014, 114, 2281-2288. [CrossRef]

21. Maulder, P.; Cronin, J. Horizontal and vertical jump assessment: Reliability, symmetry, discriminative and predictive ability. Phys. Ther. Sport. 2005, 6, 74-82. [CrossRef]

22. Blickhan, R. The spring-mass model for running and hopping. J. Biomech 1989, 22, 1217-1227. [CrossRef]

23. McMahon, T.A.; Cheng, G.C. The mechanics of running: How does stiffness couple with speed? J. Biomech 1990, $23,65-78$. [CrossRef]

24. Morin, J.B.; Dalleau, G.; Kyröläinen, H.; Jeannin, T.; Belli, A. A simple method for measuring stiffness during running. J. Appl. Biomech 2005, 21, 167-180. [CrossRef] [PubMed]

25. Landis, J.R.; Koch, G.G. The measurement of observer agreement for categorical data. Biometrics 1977, 33, 159-174. [CrossRef]

26. Spencer, M.R.; Gastin, P.B. Energy system contribution during 200- to 1500-m running in highly trained athletes. Med. Sci. Sports Exerc. 2001, 33, 157-162. [CrossRef]

27. Billat, L.V.; Koralsztein, J.P. Significance of the velocity at VO2max and time to exhaustion at this velocity. Sports Med. 1996, 22, 90-108. [CrossRef]

28. Julio, U.F.; Panissa, V.L.G.; Paludo, A.C.; Alves, E.D.; Campos, F.A.D.; Franchini, E. Use of the anaerobic speed reserve to normalize the prescription of high-intensity interval exercise intensity. Eur. J. Sport Sci. 2020, 20, 166-173. [CrossRef]

29. Nummela, A.T.; Paavolainen, L.M.; Sharwood, K.A.; Lambert, M.I.; Noakes, T.D.; Rusko, H.K. Neuromuscular factors determining $5 \mathrm{~km}$ running performance and running economy in well-trained athletes. Eur. J. Appl. Physiol. 2006, 97, 1-8. [CrossRef]

30. Casado, A.; Hanley, B.; Jiménez-Reyes, P.; Renfree, A. Pacing profiles and tactical behaviors of elite runners. J. Sport Health Sci. 2021, 10, 537-549. [CrossRef]

31. Brughelli, M.; Cronin, J.; Chaouachi, A. Effects of running velocity on running kinetics and kinematics. J. Strength Cond. Res. 2011, 25, 933-939. [CrossRef]

32. Sandford, G.N.; Rogers, S.A.; Sharma, A.P.; Kilding, A.E.; Ross, A.; Laursen, P.B. Implementing Anaerobic Speed Reserve Testing in the Field: Validation of vVO2max Prediction From 1500-m Race Performance in Elite Middle-Distance Runners. Int. J. Sports Physiol. Perform. 2019, 14, 1147-1150. [CrossRef] [PubMed]

33. Dutto, D.J.; Smith, G.A. Changes in spring-mass characteristics during treadmill running to exhaustion. Med. Sci. Sports Exerc. 2002, 34, 1324-1331. [CrossRef] [PubMed]

34. Slawinski, J.; Heubert, R.; Quievre, J.; Billat, V.; Hanon, C. Changes in spring-mass model parameters and energy cost during track running to exhaustion. J. Strength Cond. Res. 2008, 22, 930-936. [CrossRef] [PubMed]

35. Dumke, C.L.; Pfaffenroth, C.M.; McBride, J.M.; McCauley, G.O. Relationship between muscle strength, power and stiffness and running economy in trained male runners. Int. J. Sports Physiol. Perform. 2010, 5, 249-261. [CrossRef]

36. Butler, R.J.; Crowell, H.P., 3rd; Davis, I.M. Lower extremity stiffness: Implications for performance and injury. Clin. Biomech. 2003, 18, 511-517. [CrossRef] 
37. Jiménez-Reyes, P.; Casado, A.; González, J.E.; Rodríguez-Fernández, C. Influence of Hurdling Clearance on Sprint Mechanical Properties in High-Level Athletes. J. Strength Cond. Res. 2020. [CrossRef]

38. Rabita, G.; Dorel, S.; Slawinski, J.; Sàez-de-Villarreal, E.; Couturier, A.; Samozino, P.; Morin, J.B. Sprint mechanics in world-class athletes: A new insight into the limits of human locomotion. Scand. J. Med. Sci. Sports 2015, 25, 583-594. [CrossRef] 